\title{
Features of -C-C-coupling of quinoxaline-2-one with ethyl acetoacetate under acid catalysis
}

\author{
Yu.A. Azev * O.S. Koptyaeva, A.A. Mkrtchyan, T.A. Pospelova \\ Ural Federal University, 620002 Mira st., 19, Ekaterinburg, Russia \\ * Corresponding author: azural@yandex.ru
}

This short communication (letter) belongs to the Regular Issue.

(C) 2021, The Authors. This article is published in open access form under the terms and conditions of the Creative Commons Attribution (CC BY) license (http://creativecommons.org/licenses/by/4.o/).

\section{Abstract}

Quinoxalin-2-one (1) reacts with ethyl acetoacetate in trifluoroacetic acid (TFA) to form 3-(2-oxopropylideno)-3,4-dihydroquinoxaline-2one (2) and 3-(3-oxo-3,4- dihydroquinoxaline-2- $(1 \mathrm{H})-$ ylidene)methylquinoxaline-2-(1H)-one (3). The reaction product 3 was also obtained by heating the compound 1 with acetone in the presence of TFA.

\section{Keywords}

quinoxaline-2-one ethyl acetoacetate

nucleophilic substitution of hydrogen

vicarious substitution

acid catalysis

Received: 16.11.2021

Revised: 11.01.2022

Accepted: 11.01.2022

Available online: 14.01.2022

\section{Key findings}

- The replacement of hydrogen led to the formation of water, which activated the process of cleavage of the dicarbonyl group of 3-(2-oxopropylideno)-3,4-dihydroquinoxaline-2-one. The acyl group of com pound 3-(2-oxopropylideno)-3,4-dihydroquinoxaline-2-one was "vicarious" in this reaction. - The formation of 3-(3-oxo-3,4-dihydroquinoxaline-2-(1H)-ylidene) methylquinoxaline-2-(1H)-one was the result of C,C-coupling of compounds quinoxaline-2-one and 3-(2-oxopropylideno)-3,4dihydroquinoxaline-2-one, similarly to the reaction of quinoxaline-2-one 1 with acetone.

\section{Introduction}

Compounds with various types of biological activity were found among quinoxaline derivatives. $[1,2]$ Quinoxidine and Dioxidine were used as antimicrobial agents [3].

The features of the synthesis and biological activity of quinoxaline derivatives are described in the review [4]. It was previously reported that quinoxaline salts interact with acetylacetone or ethyl acetoacetate in the presence of base catalysis (diethyl and triethylamines) to form 3a,4,9,9a-tetrahydro-endo-furo[2,3-b]quinoxalines [5].

The authors of the article [6] described the cyclization of 1,3-bis(silyl-enol-ethers) and quinoxaline with the formation of 6-alkylidene-2,3-benzo-1,4-diaza-7oxobicyclo[4,3,0]non-2-yenes. There were known examples of hydrogen substitution in the heterocyclic nucleus of quinoxaline when the reactions with various C-nucleophiles were carried out in the presence of acid. As a result, $-\mathrm{C}-\mathrm{C}$-coupling products were obtained [7].

Recently [8] it was found that quinoxaline-2-one reacted with acetylacetone, benzylacetone, and heptane-3,5- dione when heated in TFA to form derivatives 6a,7dihydropyrido[1,2-a]quinoxaline-6,8-dione.

Examples of reactions of aliphatic aldehydes with quinoxalin-2-one in the presence of acid with the formation of 6-oxidopyrido[1,2-a]quinoxalinium zwitter ions were published [9].

It was also previously found that when quinoxalin-2one and phenylhydrazine hydrazones are heated in butanol in the presence of TFA, hydrogen substitution products are formed [10].

It should be noted that there have been no data on -C-C- coupling of quinoxaline-2-one with esters of $\beta$-dicarbonyl acids in the literature.

\section{Experimental}

Unless otherwise indicated, all common reagents and solvents were used from commercial suppliers without further purification.

The reaction progress and purity of the obtained compounds were controlled by thin layer chromatography 
(TLC) method on Sorbfil UV-254 plates, using visualization under UV light. Melting points were determined on a Stuart SMP10 melting point apparatus.

${ }^{1} \mathrm{H},{ }^{13} \mathrm{C}$ and ${ }^{19} \mathrm{~F}$ NMR spectra were acquired on Bruker Avance-400 and Bruker Avance NEO-600 spectrometers in DMSO- $d_{6}$ solutions, using TMS as internal reference for ${ }^{1} \mathrm{H}$ and ${ }^{13} \mathrm{C}$ NMR or $\mathrm{CFCl}_{3}$ for ${ }^{19} \mathrm{~F}$ NMR. Mass-spectra (EI, $70 \mathrm{eV}$ ) were recorded on MicrOTOF-Q instrument (Bruker Daltonics) at $250{ }^{\circ} \mathrm{C}$.

Elemental analysis was performed using a PerkinElmer 2400 Series II CHNS/O analyzer.

\subsection{Reaction of quinoxaline-2-one 1 with ethyl acetoacetate}

A mixture of quinoxaline-2-one (1) $(0.2 \mathrm{mmol})$ and ethyl acetoacetate $(0.6 \mathrm{mmol})$ was refluxed in $2.0 \mathrm{ml}$ of TFA at $110{ }^{\circ} \mathrm{C}$ in a sealed vessel for 50 hours. The solvent was removed in vacuo. The precipitate was dissolved in ethanol $(3.0 \mathrm{ml})$. The alcoholic solution was treated with water (2.0 ml) followed by treatment with $15 \% \mathrm{NH}_{4} \mathrm{OH}$ solution to $\mathrm{pH}$ 7-8 with the formation of a precipitate. The precipitate of the mixture of reaction products was filtered off.

3-(2-Oxopropylidene)-3,4-dihydroquinoxaline-2-one (2) was isolated using preparative chromatography ( $R_{\mathrm{f}}=0.156$, Silica gel Kiselgel 6o PF 254, chloroform).

Yield 35\%, m.p. $267-268^{\circ} \mathrm{C}$ ([11] $\left.267^{\circ} \mathrm{C}\right) .{ }^{1} \mathrm{H}$ NMR (400 MHz, DMSO-d6) $\delta 2.19(s, 3 \mathrm{H}), 6.06(s, 1 \mathrm{H})$, 7.08-7.13 (m, 3H), 7.37-7.40 (m, 1H), $11.86(s, 1 \mathrm{H})$, $12.96(s, 1 \mathrm{H})$. MS (IR, 70 эB), $m / z$ ( отн $\left._{\text {о }} \%\right): 202\left(\mathrm{M}^{+}, 100\right)$, 187 (M-15, 98), 159 (M-43, 60). Found, \%: C 65.28; $\mathrm{H}$ 4.99; $\mathrm{N}$ 13.88. $\mathrm{C}_{11} \mathrm{H}_{10} \mathrm{~N}_{2} \mathrm{O}_{2}$. Calculated, \%: C 65.34; $\mathrm{H} 4.98 ; \mathrm{N} 13.85$.

$3-(3-$ oxo-3,4-dihydroquinoxaline-2- $(1 H)$ ylidene)methylquinoxaline-2- $(1 H)$-one (3) was isolated by preparative chromatography $\left(R_{\mathrm{f}}=0\right)$.

Yield $5 \%$, m.p. $>300{ }^{\circ} \mathrm{C} .{ }^{1} \mathrm{H}$ NMR (400 MHz, DMSO- $d_{6}$ ) $\delta 6.87(s, 1 \mathrm{H}), 7.16-7.21(m, 6 \mathrm{H}), 7.71-7.73(m, 2 \mathrm{H})$, $11.93(s, 2 \mathrm{H}), 13.62(s, 1 \mathrm{H}) .{ }^{13} \mathrm{C}$ NMR (101 MHz, DMSO-d 6$) \delta$
$88.91,99.49,115.16, \quad 121.09,123.29,125.18,128.28$, $128.54,147.03,155.71$. MS (EI, $7 \mathrm{O} \mathrm{eV}), \mathrm{m} / z\left(I_{\text {отн }}, \%\right)$ : $304\left(\mathrm{M}^{+}, 100\right), 276$ (18), 248 (27). Found, \%: C 67.13; $\mathrm{H}$ 3.99; $\mathrm{N}$ 18.38. $\mathrm{C}_{17} \mathrm{H}_{12} \mathrm{~N}_{4} \mathrm{O}_{2}$. Calculated, \%: C 67.10; $\mathrm{H} 3.97$; N 18.41 .

\subsection{Reaction of quinoxaline-2-one 1 with acetone}

$0.5 \mathrm{mmol}$ of quinoxaline-2-one (1) was heated with $0.6 \mathrm{mmol}$ of acetone in a mixture of butanol $(2 \mathrm{ml})$ and TFA ( $0.5 \mathrm{ml})$ at $110{ }^{\circ} \mathrm{C}$ in a sealed vessel for 25 hours. The solvent was removed in vacuo. The precipitate was suspended in ethanol $(3 \mathrm{ml})$ and filtered off. The resulting precipitate of 3-(3-oxo-3,4-dihydroquinoxaline-2 $(1 H)$ ylidene) methylquinoxaline-2-(1H)-one (3) was recrystallized from DMSO and dried.

Yield 30\%. The melting point and spectral characteristics of the reaction product were similar to those obtained in the product of the interaction of quinoxaline-2-one (1) with ethyl acetoacetate.

\section{Results and discussion}

While developing effective methods for the functionalization of quinoxaline-2-one, we investigated the interactions of quinoxaline-2-one with ethyl acetoacetate under acid catalysis. We found that heating the reagents in TFA resulted in the formation of 3-(2-oxopropylideno)-3,4dihydroquinoxaline-2-one 2 (Scheme 1).

The mass spectrum of compound $\mathbf{2}$, in addition to the molecular ion peak, contained intense peaks of ions with molecular weights of $187\left(\mathrm{M}-\mathrm{CH}_{3}\right)$ and $159\left(\mathrm{M}-\mathrm{COCH}_{3}\right)$. These peaks were formed during the decomposition of ketones, which were characteristic of these compounds in common (Scheme 2).

The singlet of the protons of the methyl group in the NMR spectrum of compound 2 in DMSO- $d_{6}$ was observed at $2.3 \mathrm{ppm}$. The signal of the proton of the methine group of the enamine fragment was observed at $6.2 \mathrm{ppm}$.<smiles>CCOC(=O)CC(C)=O</smiles>

1<smiles>CC(=O)CC1=Nc2ccccc2NC1=Cc1nc2ccccc2[nH]c1=O</smiles><smiles>CCOC(=O)CC(=O)Cc1nc2ccccc2[nH]c1=O</smiles><smiles>CC=CC=CC</smiles><smiles>Nc1ccccc1NI</smiles><smiles>CC(=O)OCCC(=O)C=C1NCCNC1=O</smiles>

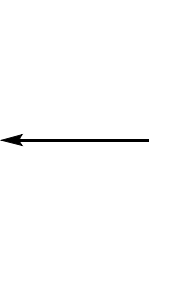<smiles>CC(=O)C1CO1</smiles>

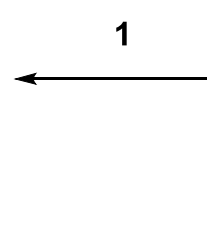

Scheme 1 The formation of 3-(2-oxopropylideno)-3,4-dihydroquinoxaline-2-one 2 


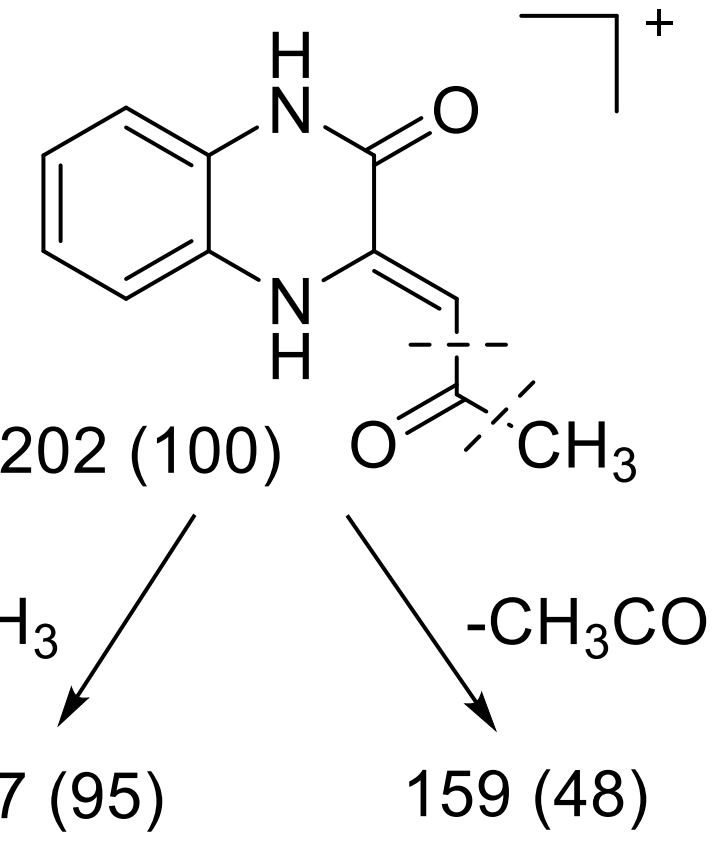

Scheme 2 The decomposition of ketones to form molecular ions

It could be assumed that the formation of the reaction product $\mathbf{2}$ proceeded through a number of stages: nucleophilic substitution of hydrogen, hydrolysis of the ester group, and decarboxylation with the formation of the final product.

Obviously, the replacement of hydrogen led to the formation of water, which activated the process of cleavage of the dicarbonyl group of compound $\mathbf{2}$.

In addition to the compound 2, 3-(3-oxo-3,4dihydroquinoxaline-2-(1H)-ylidene) methylquinoxaline-2$(1 H)$-one 3 was found in the reaction products.

In the mass spectrum of compound $\mathbf{3}$, an intense peak with $m / z 304$ was observed. It corresponded to the proposed structure.

The ${ }^{1} \mathrm{H}$ NMR spectrum of compound 3 contained the characteristic signal of the proton of the enamine fragment at $6.9 \mathrm{ppm}$. A two-proton singlet of two amide $\mathrm{NH}$-groups was observed at $11.9 \mathrm{ppm}$. The singlet of the $\mathrm{NH}$ group of the quinazoline nucleus appeared in a weak field at $13.7 \mathrm{ppm}$. The shift of this signal was apparently due to the presence of a hydrogen bond between the $\mathrm{NH}$ group of quinazoline and the $\mathrm{N}$-atom of another quinoxaline nucleus.

The formation of compound $\mathbf{3}$ was the result of $-\mathrm{C}-\mathrm{C}-$ coupling of quinoxaline-2-one $\mathbf{1}$ with a new $\mathrm{C}$-nucleophilic agent, which was formed during the reaction, compound 2. Apparently, the acyl group of compound $\mathbf{2}$ was "vicarious" in this process.

The ompound 3 was also obtained by heating the compound $\mathbf{1}$ in acetone in the presence of TFA.

Obviously, the formation of $\mathbf{3}$ was the result of C,C-coupling of the compounds $\mathbf{1}$ and $\mathbf{2}$, similarly to the reaction of quinoxaline-2-one $\mathbf{1}$ with acetone.

\section{Conclusions}

In conclusion, it should be noted that the synthesis of alkylated derivatives of quinoxaline-2-one was carried out earlier [11] by the interaction of 1,2-dihydroquinoxaline 4-oxide with active methylene compounds in the presence of piperidine. Nevertheless, direct alkylation of quinoxaline-2-one with ethyl acetoacetate under conditions of acid catalysis was described by us for the first time.

\section{Declaration of competing interest}

The authors declare that they have no known competing financial interests or personal relationships that could have appeared to influence the work reported in this paper.

\section{References}

1. Barlin GB. The Chemistry of Heterocyclic Compounds: The Pyrazines. New York: Wiley-VCH; 1982. 687 p. doi:10.1002/9780470187173

2. Cheeseman GWN, Cookson RF. The Chemistry of Heterocyclic Compounds: The Condensed Pyrazines. New York: Wiley-VCH; 1979. 843 p.

3. Mashkovsky MD. Lekarstvennyye sredstva [Medicines]. Moscow: Nauka; 1993. 347 p. Russian.

4. Sakato G, Makino K, Kurasawa Y. Recent progress in the quinoxaline chemistry. Synthesis and biological activity. Heterocycles. 1988;27(10):2481-515. doi:10.3987/REV-88-397

5. Chupakhin ON, Charushin VN, Klyuev NA, Rezvukhin AI, Semion VA. Cyclization of N-alkylazinium cations with bisnucleophiles. 3.endo adducts in the reaction of quinoxalium salts with $\beta$-diketones and their $\mathrm{x}$-ray diffraction analysis. Chem Het Comp. 1981;17:1046-52. doi:10.1007/BF00503539

6. Schmidt A, Guetlein J-P, Langer P. Synthesis of 6-alkylidene2,3-benzo-1,4-diaza-7-oxabicyclo[4-3.0]non-2-enes by cyclization of 1,3-bis(silyl enol ethers) with quinoxalines. Tetr Let. 2007;48:2067-2069. doi:10.1016/j.tetlet.2007.01.147

7. Azev YuA, Kodess MI, Ezhikova MA, Gibor AM, Baranov VI, Ermakova OS, Bakulev VA. New opportunities for the synthesis of quinoxaline-substituted heterocyclic and aryl moieties. Pharm Chem J. 2013;9:498-502. doi:10.1007/s11094-013-0989-Z

8. Azev YuA, Kodess MI, Ezhikova MA, Ermakova OS, Berseneva VS, Bakulev VA. Reactions of quinoxaline-2-one with $\beta$ diketones: a new approach to 6a,7-dihydro-5H-pyrido[1,2a]quinoxaline-6,8-diones. Mend Comm. 2017;1:97-98. doi:10.1016/j.mencom.2017.01.032

9. Azev YuA, Ermakova OS, Berseneva VS, Kodess MI, Ezhikova MA, Ganebnykh IN. Synthesis of the 6-oxidopyrido[1,2a]quinoxalinium derivatives from quinoxaline-2-one and aldehydes - new examples of domino reactions. Mend Comm. 2017;27:637-639. doi:10.1016/j.mencom.2017.11.034

10. Azev YuA, Koptyaeva OS, Tsmokalyuk AN, Pospelova TA, Bakulev VA. Benzaldehyde phenylhydrazones as C-nucleophiles for functionalization of quinoxaline-2-one. Unusual transformations of indole-3-carbaldehyde phenylhydrazones. AIP Conf Proc. 2020;2280:0018799. doi:10.1063/5.0018799

11. Tennant G. Heterocyclic N-oxides. Part II. Nucleophilic reactions of 1,2-Dihydro-2-oxoquinoxaline 4-oxide. J Chem Soc. 1964;1982-1986. 